\title{
Разорванная на части изнутри: Украина и уроки для глобальной безопасности
}

\section{Ирина Клименко}

Институт стратегических исследований "Новая Украина», Киев, Украина

\begin{abstract}
Резюме: Нестандартная интервенция России на Украине была реализована в четырех главных областях - в экономической системе в целом, в энергетическом секторе и секторе безопасности, и в информационной политике. Продуманная политика Кремля превратила Украину в экономически хрупкую и институционально слабую страну. Благодаря усилиям бывшего режима и российским разведывательным службам, основные украинские государственные институции были вовлечены в полулегальные, полукриминальные транснациональные бизнес схемы. Макрофинансовая уязвимость Украины, в сочетании с деформированной экономической структурой, оказались необходимыми и достаточными условиями для подготовки и осуществления гибридной агрессии. Украинский прецедент может быть использован заново в качестве специальной операции для разрушения государственности, при которой распад достигается эскалацией внутренних политических и экономических проблем. Одним из универсальных средств подрыва государственности в эпохе гибридных войн является поощрение коррупции среди обладателей самых высоких должностей.
\end{abstract}

Ключевые слова: интервенция, политика безопасности, гибридная война, информационная война, систематическая коррупция, незаконная экономика, криминальный бизнес.

\section{Введение}

Украина переживает очень трудный период своей истории. Страна прощается со своим советским прошлым, в то время, как Российская Федерация (РФ) пытается восстановить "Советскую империю», удерживая Украину в своей сфере контроля. Драма Украины происходит «онлайн» на наших гла- 
зах, и события разворачиваются с такой скоростью, что эксперты и теоретики не только не в состоянии следить за деталями, но затруднены понять, что вообще происходит.

Краткая хронология кризиса, который привел к «странной» войне Россия-Украина, такова. После обеда 21 ноября 2013 года молодые украинцы собрались вместе для мирного протеста против решения правительства приостановить процесс интеграции Украины в Европейский Союз; около 2000 человек пришли на Площадь Независимости (Майдан Незалежности) Киева. Однако, после провала на саммите Восточного партнерства в Вильнюсе 28-29 ноября, ранним утром 30 ноября последовал насильственный разгон палаточного городка. 1 декабря на Майдане собралась толпа граждан, по разным оценкам, численностью от 400000 до 800 000. ${ }^{1}$ Их действия имели определенно антипрезидентский и антиправительственный характер. Напряженность в отношениях между протестующими и силами безопасности быстро росла и привела к многочисленным стычкам между ними. Украинское руководство впустую пыталось прекратить протесты. 16 января, с грубейшим нарушением процедурных правил, украинский парламент одобрил анти-протестные законы, которые сильно ограничивали конституционные права протестующих. 19 января 2014 года конфронтация драматически усилилась и привела к перестрелкам между радикальными демонстрантами и полицией. За период 21-23 января трое человек погибли от огнестрельных ран, и множество протестующих получили ранения. К 18 февраля еще одна эскалация ситуации привела к массовому кровопролитию. По сведениям украинского министерства здравоохранения, в Киеве с 18 по 21 февраля погибли 77 человек, а министерство внутренних дел сообщило о гибели 16 полицейских.

Этот день стал поворотным пунктом, и в течении следующих нескольких дней произошел сдвиг в государственной власти. 23 февраля украинский парламент возложил обязанности президента Украины на Председателя Верховной рады (однокамерного парламента), Александра Турчинова. В периоде 23-27 февраля последовала смена исполнительных органов Севастополя и Автономной Республики Крым. Новые власти в Крыму не признали законность нового украинского правительства и обратились к руководству РФ за содействием и помощью. Затем, через несколько недель, новое руководство Автономной Республики Крым и Севастополя односторонним образом объявили независимость Крыма и провели референдум. 18 марта было подписано соглашением между РФ и Республикой Крым о принятии Республики Крым в состав России. После аннексии Крыма фокус напряжения сместился к юго-востоку Украины. Иными словами, члены местных органов власти в некоторых восточных регионах по-

1 “1 December 2013 Euromaidan riots," Wikipedia: The Free Encyclopedia, доступно на http://en.wikipedia.org/wiki/1_December_2013_Euromaidan_riots (по состоянию на 5 августа 2014). 
следовали примеру Крыма, отказываясь признать власть Киева и приняли резолюции, декларирующие их готовность принять на себя ответственность за защиту конституционного порядка на своей территории. Кроме того, они заявили, что последние события в Киеве привели к параличу центральной власти и дестабилизации всей страны.

7 апреля 2014 года, действующий президент Украины Александр Турчинов объявил о начале «антитеррористической операции». 12 апреля террористы захватили первый город - Славянск. Прямые последствия этой острой фазы социального и политического кризиса показывают, что Украина стала объектом нового вида агрессии, которая отличается следующим:

- аннексия Автономной Республики Крым (оккупация и незаконное включение в состав РФ);

- дестабилизация западных и восточных регионов Украины и подстрекательство к сепаратизму (вооруженные конфликты с участим сил специального назначения и вооруженных наемников иностранного происхождения, в основном из РФ; образование новых государств и попытки незаконного изменения конституционного порядка Украины);

- нежелание соблюдать и на практике несоблюдение РФ целого ряда двусторонних регуляторных соглашений и договоров, формирующих основу украино-российских отношений (на первом месте Договора о дружбе, сотрудничестве и партнерстве между Украиной и РФ);

- ведение информационной войны против Украины, беспрецедентной по размаху в отношение фальсификаций и инсинуаций;

- дискредитирование существующих международных договоров, гарантирующих безопасность и целостность украинского государства (границы, невмешательство во внутренние дела, экономическая безопасность и т.д.);

- де факто аннулирование Будапештского меморандума о гарантиях безопасности от 1994 года, в соответствии с которым ядерные государства гарантируют безопасность Украины; разрушение режима нераспространения. ${ }^{2}$

В то же время есть основания считать, что РФ тайно готовила подрыв украинской государственности. Еще в 2008 году украинские специальные службы были информированы о планах РФ захватить Крымский полуостров, как показывают данные рекогносцировочных миссий, которые были предприняты. ${ }^{3}$ Наряду с этим, на саммите НАТО-Россия в Бухаресте в 2008

2 Подробнее в: “Memorandum. Lessons from the Ukraine Crisis: New Approaches to Security Policy (global, regional, national)" ("New Ukraine" Institute of Strategic Studies, 5 June 2014), доступно на http://newukraineinstitute.org/new/399 (по состоянию на 26 июля 2014).

3 Иван Капсамун, «О «линии водораздела», Интервью с Валентином Наливайченко», День, 19 июня 2014, доступно на http://www.day.kiev.ua/ru/article/ podrobnosti-intervyu/o-linii-vodorazdela. 
году президент РФ Владимир Путин заявил, что Украина является искусственным государством, в котором проживают семнадцать миллионов русских. Через месяц РФ внесла изменения в национальном законодательстве, предоставив себе право «защищать» русское население, находящееся за ее границами. Соответственно, с большим доверием следует отнестись к утверждениям некоторых экспертов, что в 2008 году РФ начала осуществлять новый вид необъявленной агрессии против Украины, используя методы, которые дали «начальный импульс» и/или «разбудили» внутренние молекулярные конфликты (т.е. неконвенциональная или гибридная война, нестандартные вооруженные конфликты и т.д.). ${ }^{4}$ В результате этого, весной 2014 года эта война перешла от скрытой к открытой фазе.

\section{Трансформация Украины под давлением агрессора}

Тогда, в 2008 году, декларация Путина выглядела больше как пожелание. Через пять лет, в 2013 году, Украина Януковича-Путина опасно приблизилась к грани, за которой украинская государственность де факто - и возможно, де юре - перестала бы существовать. Согласованные действия российских чиновников привели к тому, что так называемая «вертикаль Януковича» была тесно встроена в систему, которая делала осуществление российских интересов реальностью. Нестандартная интервенция РФ на Украину (до 2014 года) осуществлялась в четырех основных областях - в экономической системе в целом, в энергетический сектор, в сектор безопасности и в информационную политику.

Российский президент был хорошо информирован о специфике корпоративного государства экс-президента Януковича. Это давало ему основание утверждать, что Украина «не является государством» в обычном смысле этого слова, и основываясь на этом понимании, определять допустимый уровень влияния на внутреннюю и внешнюю политику Украины. Если личное обогащение было высочайшей целью Януковича во всех сферах жизни страны, для режима Путина спектр задач был значительно шире. В экономической сфере цель РФ состояла в том, чтобы тесно обвязать Украину с Россией, не позволяя никакого согласования с Европейским Союзом или США, и препятствование институциональной и структурной

4 Одним из наиболее последовательных приверженцев этого подхода является А. Илларионов, старший научный сотрудник института Като, бывшего советника президента России и бывшего директора Института экономических анализов. $\mathrm{K}$ примеру, в своем заявлении в Комитете по иностранным делам Палаты представителей США во время слушаний в 2009 году “От соперничества к сотрудничеству: укрепление отношений США-Россия», он представил список из девяти "неконвенциональных» войн, начатых Российской Федерацией. Доступно на www.cato.org/publications/congressional-testimony/competition-collaborationstrengthening-usrussia-relationship. 
модернизации экономики. ${ }^{5}$ Усиление энергетической зависимости Украины облегчает достижение этих целей, поскольку расширяет возможности Кремля проводить политику энергетического владычества на международном уровне. ${ }^{6}$ В итоге, трансформирование государственных институций в централизованную систему и выкачивание ресурсов из экономики создало для РФ широкие возможности «покупать оптом политическое и военное руководство страны» и «клонировать» внутри Украины квазигосударство по российской модели. ${ }^{7}$

Информационные интервенции, преследующие двойную цель агрессии и заблуждения, использовали многочисленные методы информационной и психологической войны, простирающиеся от опубликования тенденциозной информации и полуправды до откровенной лжи (обмана). Направленная на поддержку коммуникационного и организационного обеспечения хищнических целей РФ на Украине, эти информационные интервенции создали специфическую «картину мира», предназначенную для российских и украинских граждан. К примеру, масштабная пропагандистская кампания, которая сопутствовала подготовке и проведению специальных операций по аннексии Крыма, охватывала несколько областей. Она была направлена на достижение нескольких ключевых целей: (1) деморализовать украинское население; (2) деморализовать вооруженные силы и органы безопасности и побудить их к государственной измене; (3) создать искривленную «медиа картину» событий в умах российских и украинских граждан; (4) создать иллюзию массовой поддержки действий РФ среди населения юго-восточных регионов Украины; (5) оказать психологическую поддержку приверженцам радикального обвязывания восточных и южных регионов Украины с Россией; (6) воздействовать на западные СМИ, чтобы отражали события с пророссийским уклоном.

Контроль над сектором безопасности Украины обеспечивал координацию всех компонентов российской агрессии против Украины на этапе

5 Ирина Клименко и др., Перспективы отношений между Украиной и Таможенным Союзом Республики Беларусь, Республики Казахстан и Российской Федерации (Киев: Национальный институт стратегических исследований, 2011), 59.

6 Ирина Клименко и др., Украина в интеграционных процессах на постсоветском пространстве: моделирование альтернатив (Киев: Национальный институт стратегических исследований, 2013), 44.

7 Address by Andrey Illarionov, Senior Fellow at the Center for Global Liberty and Prosperity, Cato Institute, Washington, D.C., at a meeting of the Economic and Security Committee of the NATO Parliamentary Assembly, Vilnius, 31 May 2014, доступно на http://www.youtube.com/watch?v=J8ISQpbfoBI (по состоянию на 23 июля 2014). Версия на русском языке доступна на http://aillarionov.livejournal.com/ 696982.html (по состоянию на 23 июня 2014).

8 «О информационном и психологическом компонентах агрессии Российской Федерации против Украины», на основе событий 1-2 марта 2014 (Киев: Национальный институт стратегических исследований, 2014), доступно на http://en.niss.gov.ua/public/File/englishpublic/Russia_aggression.pdf (по состоянию на 23 июня 2014). 
скрытой агрессии. Доступ к оперативному руководству сектором безопасности позволял РФ осуществлять ежедневный контроль над информационными потоками в Украине - в том числе и над компрометирующей информацией о представителях государства на самом высоком уровне. Это препятствовало принятию каких бы то ни было политических решений, неугодных РФ, и устраняло другие угрозы, мешающие достижению целей РФ на региональном и глобальном уровне. По свидетельству Валентина Наливайченко, главы Службы Безопасности Украины (СБУ), «... 'наследство' Службы Безопасности Украины, оставшееся после руководства Якименко и в целом после Януковича, было страшным ударом для безопасности нашей страны. Люди, которые позволили этому случиться, - и которые на практике помогали врагу, - по существу являются государственными преступниками». ${ }^{9}$

Как можно предполагать в результате аннексии Крыма, стратегической целью специальных служб РФ было лишение Украины способности защитить себя в случае открытой агрессии, и эта цель была достигнута. Как раз в этой ситуации новые руководители страны установили, что практически не существует украинской системы обороны. Украинские эксперты, которые изучали и восстанавливали мотивы, определяющие разные решения в сфере военной безопасности, которые обусловили потерю оборонительных способностей украинской армии, пришли к заключению, что продолжается скрытое влияние РФ на вопросы, связанные с государственным менеджментом оборонного сектора на тактическом и стратегическом уровне. $^{10}$ Персональные назначения на исполнительные должности в вооруженных силах, менеджмент, финансовые, и особенно политические решения по вопросам обороны Украины постоянно были объектом вмешательства и влияния со стороны РФ. Как отмечено в вышеупомянутом исследовании, последние министры обороны Украины (в правительстве Януковича) были гражданами РФ. ${ }^{11}$

Несмотря на широко распространенное мнение, что Путин не мог полностью рассчитывать на мимолетную лояльность украинского президента, в лице Януковича он имел приверженца, единомышленника и последователя, поскольку режимы, которые создавали оба в своих государствах, были одного и того же типа. Нет сомнений, что Украина Януковича была дополнением России Путина, хотя имелись определенные отличия, касающиеся методов криминального мира.

9 Капсамун, «О линии водораздела», День, 19 июня 2014.

10 Для подробностей, смотри: О снижении (частичной потере) оборонных способностей Украины (2000-2014). Экспертное исследование (Киев: Центр исследований по вопросам армии, конверсии и разоружению, Defense Express, 2014),

11 доступно на http://issuu.com/ukrainian_defense_review/docs/.

Там же, 76. 


\section{Взятие Украины}

После того, как Янукович сбежал и власть в Украине перешла в другие руки, постепенно начали накапливаться, подвергаться анализу и обобщению изолированные сведения о масштабе эрозии национальной идентичности. Однако, в целостной картине остается множество пробелов. Важные свидетельства или были безвозвратно утеряны, или умышленно скрывались от общественности. ${ }^{12}$ Официальные украинские органы все еще не закончили свои расследования и не обработали всю информацию, которой располагают. Поэтому, в публичном дискурсе преобладают восприятия, основанные больше на журналистских материалах, чем на официальных источниках. К примеру, изучение объектов и материалов, которые просто невозможно переместить из резиденции Януковича из-за нехватки времени, указывает на то, что этот человек был патологически одержим своим личным обогащением. ${ }^{13}$

Иерархия коррупции была структурирована так, чтобы обеспечивать непрерывный поток денег и материальных ресурсов, начиная от сбора дани от хозяев маленьких магазинов, взяточничества, продажи должностей и рейдерского захвата бизнесов до незаконного присваивания бюджетных фондов. В этой системе, каждая государственная институция, каждый элемент государственного управления был предназначен для генерирования доходов в пользу личного обогащения экс-президента и его окружения. Соответственно, оборонные ведомства и органы охраны правопорядка использовались прежде всего для обслуживания личных экономических интересов пособников режима: (1) сбор информации (экономической, финансовой, компрометирующей и т.д.) о потенциальных жертвах; (2) принуждение (шантаж или использование силы); (3) сбор выплат (законных и незаконных); и (4) обеспечение безопасности иерархии власти и системы контроля, которая она создала.

В апреле 2014 года Государственная финансовая мониторинговая служба обнародовала промежуточные выводы (для марта) расследования отмывания денег, полученных в результате коррупции и злоупотреблением государственными фондами и государственной собственностью бывшим президентом Украины и его родственниками, а также представителями бывшего управления и его пособников. Согласно этим материалам, общая сумма финансовых транзакций, относительно которых есть подозрения, что они связаны с легализованием незаконно полученных доходов, доходит до 77.2 миллиардов гривен (около девяти миллиардов дол-

12 По свидетельству главы Службы безопасности Украины, начиная с декабря 2013 года, соучастники экс-президента начали систематически уничтожать существующие записи о беспрецедентных кражах и других преступлениях режима.

13 «Активы Януковича: публичная инициатива по сбору информации о неофициальных активах экс-президента Януковича и его пособников», доступно на http://Yanukovych.info/ru/viktor-yanukovych/. 
ларов США). По случайности, это число отсутствует в англоязычной версии вебсайта ведомства. ${ }^{14}$

После прихода к власти в 2010 году Янукович создал строгую вертикальную иерархию для управления потока денег, устранив соперников и упростив оперативный контроль за поставками налички. ${ }^{15}$ Очевидно, что система экспроприации денег из украинской экономики была усовершенствована до такого состояния, что количество богатств, накопленных за время власти Януковича, сравнимо со всем национальным бюджетом страны. Анализ рисков выполнения национального бюджета за 2014 год, подготовленный во время мандата Януковича, дает возможность измерить масштаб амбиций экс-президента в последнем году его нахождения у власти (следующие президентские выборы были запланированы на начало 2015 года). По оценкам экспертов, возможные потери бюджета, проистекающие из схем, имеющих характер коррупционных рисков, доходили до около 24 миллиардов долларов США (или почти половины бюджетных расходов). ${ }^{16}$

При подготовке настоящего материала автор нашел большое число свидетельств и оценок независимых СМИ, описывающих схемы для незаконного присваивания фондов из украинской экономики. На практике, общее количество украденных ресурсов - от 17 до 30 миллиардов долларов, по разным оценкам - сегодня используется для финансового обеспечения необъявленной войны в Донбассе. Кроме того, интересно отметить, что некоторые элементы этих схем были задействованы задолго до времени Януковича. Налоговые махинации, наряду со схемами контрабанды и газовыми схемами, стали наиболее прибыльными секторами теневой экономики, вызывая яростную конкуренцию для их контроля, не исключая и соперничество для победы на президентских выборах и получения большинства в парламенте. Вряд ли можно полагать, что эти схему ушли вместе с экс-президентом Януковичем. Чтобы оценить масштаб деградации государственных институций и лучше понять проблемы, с которыми сталкиваются новые украинские руководители с учетом конфликта в Восточной Украине, стоить рассмотреть источники накопленных Януковичем богатств.

Пример 1. По оценкам Министерства налогов и сборов, потери от так называемых «налоговых ям» (компаний, уклоняющихся от уплаты налогов

14 "Information from the State Financial Monitoring Service" (9 April 2014). По состоянию на 28 июля 2014 на http://www.sdfm.gov.ua/news.php?news_id=2546\& lang=uk; http://www.sdfm.gov.ua/news.php?news_id=2592\&lang=en.

15

Некоторые информированные источники в частных разговорах указывали, что Янукович предпочитал хранить деньги не в банке, а накапливать их в виде налички, золота и изделий из драгоценных материалов. Это косвенно подтверждается видеозаписями камер наблюдения его резиденции, ставшими доступными после его бегства.

16

Ivan Sikora, "Budget-2014: Systemic Risks Costing over 188 Billion UAH" (Open Society Foundation, 14 January 2014), доступно на http://osf.org.ua/policy-analysisparlament/view/88. 
на прибыль) за 2011-2013 достигли 37 миллиардов долларов (т.е. 12.5 миллиардов за год). ${ }^{17}$ Эта схема пронизывала всю бюджетную систему Украины и находилась под контролем руководителями Государственной налоговой администрации, Государственного таможенного комитета и других регуляторных органов. Каждая из этих государственных институций была обязана регулярно переводить фиксированную сумму наличности сотрудникам Януковича.

Пример 2. Общественные поставки являются еще одним полностью коррумпированным методом выкачивания ресурсов из экономики. Как правило, только компании, связанные с высокопоставленными личностями, могут официально выиграть тендеры на выполнение больших государственных проектов. ${ }^{18}$ Кроме того, цена проектов, выставляемых на соревновательные торги, завышена как минимум в два раза. Объем неоправданных расходов только из центрального бюджета, и только на государственные поставки, оценивается в 10 миллиардов долларов. ${ }^{19}$

Пример 3. Контроль над государственными активами и доступ к управлению и финансовым ресурсам государственных компаний сделал возможным, с одной стороны, манипулировать активами, находящимися под их контролем, и с другой стороны, кражу ресурсов, отдавая в наем ресурсы, полученные с предоставлением государственных гарантий. К марту 2014 года общая задолженность государственных компаний была 140 миллиардов украинских гривен (около 13 миллиардов долларов США). Все эти компании, как и многие другие государственные компании (к примеру, Энергоатом, которая производит электричество в атомных электростанциях) являются убыточными предприятиями, т.е. они не могут функционировать без поддержки из государственного бюджета. Компания Нафтогаз, монопольный оператор на украинском газовом рынке, является исключением. Задолженность компании кредиторам (7.7 миллиардов долларов) получена в основном в результате махинаций, направленных на выкачивание финансов компании. По разным оценкам, компаньоны Януковича делали более 3 миллиардов долларов в год на этих схемах. ${ }^{20}$

17 Minutes of a plenary session of the Supreme Rada of Ukraine (Parliament of Ukraine), 19 June 2014, доступно на http://iportal.rada.gov.ua/meeting/stenogr/ show/5641.html.

$18 \mathrm{~K}$ сожалению, эта практика продолжается на вебсайте, созданном независимыми журналистами для прослеживания коррупционных связей при государственных поставках, регулярно появляется новая информация; доступно на http://nashigroshi.org.

19 Sergey Lyamets, "Vladimir Dubrovksy: The Top-Down Power Structure Must Be Destroyed," Ekonomichna Pravda [Экономическая правда], 18 June 2014, доступно на http://www.epravda.com.ua/publications/2014/06/18/466239/ (на русском).

20 К примеру, нефтяная и газовая компания «Нафтогаз» покупает 18 миллиардов кубических метров природного газа, производимого внутри страны, по цене в 53 доллара за 1000 кубических метров. Декларированная цель этой низкой цены, это социальные потребности - продажа дешевого газа бедным потребителям. На практике, до половины газа продается по раздутой цене российского 
Пример 4. Только компании, которые либо принадлежали окружению бывшего президента или делились прибылями с ним (обычно 30-50\%), пользовались поддержкой со стороны государства. Только в угольной промышленности бюджетные субсидии на добычу угля удвоились - до 1.5 миллиардов - за период с 2009 по 2013 год. ${ }^{21}$ Нелегальная добыча угля была вторым элементом схемы субсидирования угледобычи. К началу 2014 года добыча угля в незарегистрированных шахтах достигла рекордный уровень в шесть миллионов метрических тонн, или на практике $10 \%$ всего угля, добываемого в стране. ${ }^{22}$ Прямой приход от незаконной деятельности оценивается в 250 миллионов долларов США в год. ${ }^{23}$

Если предположение, что российская и украинская политические и экономические системы функционировали дополняющим друг друга образом в период, приведший к украинскому кризису в конце 2013 года обосновано, то следует, что главные политические цели Януковича и Путина совпадали. Первый пытался укрепить преступный и коррумпированный режим, второй сохранить Украину как недемократическое и несвободное государство в зоне, контролируемой РФ. Очевидно, украинский экс-президент принял окончательное решение порвать отношения с Западом летом 2013 года. Это заключение основано на личных впечатлениях автора и сведениях о текущих проблемах высшего руководства Украины. В частности, опасения, связанные с предстоящими выборами, надвигающийся экономический кризис и политический шантаж со стороны РФ, часто находили выражение на заседаниях президентской администрации и правительства. Таким образом, решение бывшего президента обуславливалось следующими мотивами: 1) угроза потери источников персонального обогащения в результате надвигающегося финансового и экономического кризиса; 2) отсутствие перспектив на быстрое компенсирование доходов в результате интеграции с $\mathrm{EC}^{24}$ и угроза распада схем обогащения в результате осу-

газа (485 \$ США), поскольку у Украины нет централизованной системы учета газовых поставок и конкурентного газового рынка. Sikora, "Budget 2014."

22 На практике, начальная цена нелегального газа в несколько раз ниже рыночной цены. Однако, после легализации этого газа, как будто он добыт в государственных скважинах, его цена увеличивается в несколько раз. Таким образом, хозяева незаконных газовых скважин делают деньги два раза - на махинациях с ценой и на субсидиях из бюджета.

23 “Кабмин утвердил план борьбы с нелегальной добычей угля," Профсоюз работников угольной промышленности Украины, 13 января 2014, доступно на http://www.prupu.org/news/18361/.

24 Андерс Ослунд, эксперт по экономикам постсоветских государств, отмечает, что сумма из десяти миллиардов долларов США, которую бывший первый заместитель премьера Арбузов пытался получить у ЕС, по скромным оценкам является как раз той суммой, которая исчезла из национального бюджета в результате их махинаций. Anders Åslund, "Payback Time for the 'Yanukovych Family,"' RealTime Economic Issues Watch, 11 December 2013, доступно на http://blogs.piie.com/ realtime/? $\mathrm{p}=4162$. 
ществления ассоциации; и 3) предположение, что Путин согласится пойти навстречу финансовым нуждам Януковича, государственным и личным (кредиты и доступ к газовым сделкам).

Революционные события на Майдане в Киеве обернулись угрозой, которую не учли ни Янукович, ни Путин. Соответственно, оба лидера сделали все возможное, чтобы подавить протесты. ${ }^{25}$ Накануне открытой агрессии Украина была на грани дефолта, а ее государственные институции (армия, полиция, система правосудия, службы безопасности и большинство национальных органов исполнительной власти) были полностью обессилены. ${ }^{26}$

Ко времени, когда кризис достиг кульминации, основные сектора украинской экономики были вовлечены в полулегальные, полукриминальные транснациональные бизнес схемы. Элементы бюджетной и налоговой политики использовались для незаконного выкачивания существенной части ВВП из экономики.

В результате целенаправленной политики Кремля, с помощью членов бывшего украинского режима и российских служб безопасности, Украина была превращена в экономически уязвимое и институционально слабое государство. Для международных наблюдателей, аннексия Крыма стала поворотным пунктом в понимании украинского кризиса. Однако, потеря Крыма была только началом открытой фазы нашествия. Для понимания стратегии и тактики интервенции ключевым является анализ ситуации с точки зрения политических и экономических реалий. Соответственно, неконвенциональная война против Украины началась задолго до того, как на нее обратили внимание. В эпохе гибридных войн угрозы тоже стали гибридными - нечеткими, завуалированными, искривленными и т.д. Когда агрессор ограничен (по разным причинам) в использовании традиционных

25 Капсамун, «О линии водораздела». По свидетельству СБУ, по крайней мере три группы высокопоставленных должностных лиц из ФСБ Российской Федерации работали в Службе безопасности Украины с декабря 2013 по февраль 2014. В эти месяцы все современное вооружение, персональные дела, архивы - все, на чем основывается современная профессиональная служба безопасности, было направлено в Крым. В последние годы российские агенты, которые имели постоянное присутствие в подразделениях украинской службы безопасности, во время революционных действий активно работали для создания и реализации планов по подавлению этих действий (расчистка Майдана, похищение активистов, стрельба по людям). Кроме того, режим Путина, предположительно в координации с Януковичем, готовился к аннексии Крыма и событиям в Донбассе. Еще в марте 2014 СБУ выявила сепаратистские организации на территории Луганской и Донецкой областях, которые на практике были подрывными группами. У них были запасы оружия и денег. Было установлено также, что бывший командующий внутренних войск, бывший министр внутренних дел Захарченко и бывший глава СБУ участвовали в наборе наемников и организации переправки оружия на территорию Украины.

${ }^{26}$ Ukraine. Request for a Stand-By Arrangement, IMF Country Report 14/106 (Washington: International Monetary Fund, 2014), доступно на http://www.imf.org/external/ pubs/ft/scr/2014/cr14106.pdf. 
оружий, он использует заместители. В случае с Украиной ясно, что применение нестандартной тактики «направленного срыва» работы управляющих органов врага и экономической системы дает агрессору очевидное преимущество без использования вооруженной конфронтации.

В конце июля 2014 года, когда работа над этой статьей близилась к завершению, появилась хрупкая надежда на быстрое завершение странной войны в Донбассе. Однако, в среднесрочном плане трудно реализовать перспективы на установление устойчивого мира. Есть основания предполагать, что социальные и экономические проблемы, с одной стороны, и недовольство среди олигархических кругов результатом горячей фазы конфликта с другой, будут провоцировать и искушать агрессора на новые и новые попытки срыва нормальной жизни на Украине.

\section{Выводы и рекомендации для Украины}

Агрессивная политика РФ привела к многократному увеличению рисков трансрегионализации конфликта, распространению вооруженных действий в другие страны (на первом месте к соседям Украины), дестабилизации пограничных территорий, интенсификации сепаратистских процессов и в итоге, к эскалации угроз безопасности в Центральной Европе и регионах Балтийского и Черного моря.

Украинский прецедент может быть повторен в качестве специальной операции по уничтожению государственности, при которой распад достигается путем эскалации внутренних политических и экономических проблем (стран, регионов и международных блоков). Универсальным средством подрыва государственности в эпохе гибридных войн является поощрение коррупции среди людей, занимающих самые высокие должности и опора на систематическую коррупцию в институционально слабых государствах.

В случае с Украиной, макрофинансовая уязвимость в сочетании с деформированной экономической структурой оказались необходимыми и достаточными условиями для подготовки и осуществления гибридной агрессии на соседнее государство. Обстоятельства, сопровождающие развязывание вооруженного конфликта в Восточной Украине, дали достаточно свидетельств в пользу тезиса, что специфические экономические интересы участников конфликта способствуют возникновению конфликта и препятствуют его прекращению. ${ }^{27}$

27 Paul Collier, "Economic Causes of Civil Conflict and Their Implications for Policy," in Leashing the Dogs of War, ed. Chester A. Crocker et al. (Washington, D.C.: USIP Press, 2007), доступно еще на http://users.ox.ac.uk/ econpco/research/pdfs/ EconomicCausesofCivilConflict-ImplicationsforPolicy.pdf. CM. еще Ivan Briscoe, "Non-conventional armed violence and non-state actors: challenges for mediation and humanitarian action," The Norwegian Peacebuilding Resource Centre (NOREF), Report, May 2013, доступно на http://www.peacebuilding.no (по состянию на 20 июля 2014); Mark B. Taylor, “Conflict Financing: What's Wrong with War Econo- 
Основываясь на этом, можно дать три важные рекомендации для Украины. Во-первых, страна должна полностью реструктурировать свой сектор безопасности, службы охраны правопорядка и вооруженные силы. Рисками, связанными с решением этих задач, являются нехватка персонала, измена, отсутствие опыта и ресурсов. Во-вторых, необходимо расширить административный и финансовый потенциал институций государственной власти и разрушить вертикальную структуру коррупции. Решение этой задачи включает соблюдение строгой антикоррупционной политики и осуществление институциональных и структурных реформ в сферах деятельности в наибольшей степени участвующих в незаконных схемах (т.е. бюджет, общественные поставки, банковое дело и энергетика). И последнее, надо уничтожить финансовую базу сепаратистского движения и теневой бизнес в Донбассе и в других регионах, который служит социальным прикрытием для «сепаратистского» движения должен быть прекращен. В число рисков входят невозможность полного перекрытия каналов, по которым ресурсы поступают из РФ, отсутствие контроля над захваченными территориями и над центрами криминального бизнеса, и ослабление или разрушение систем социального обеспечения для лиц, желающих уйти из зоны конфликта.

\section{6 авторе}

Ирина Клименко выпускник Европейского центра исследований по вопросам безопасности имени Джорджа К. Маршалла (ЕЦИВБ 11-10), в настоящее время работает как главный консультант Института стратегических исследований «Новая Украина» в Киеве. В 2010-2014 годах она была руководителем Департамента внешней политики Национального института стратегических исследований при администрации президента Украины. Она кандидат экономических наук (2001), специализируется по вопросам сотрудничества с международными организациями.

E-mail: iryna.klimenko@gmail.com.

mies?" The Norwegian Peacebuilding Resource Centre (NOREF), Report, May 2013, доступно на http://www.peacebuilding.no/ (по состоянию на 23 июля 2014). 